\title{
Kabinet grafike Hrvatske akademije znanosti i umjetnosti: formiranje i profiliranje specijalističke muzejsko-galerijske institucije
}

Marković, Slavica

Source / Izvornik: Institucije povijesti umjetnosti : zbornik 4. kongresa hrvatskih povjesničara umjetnosti, 2019, 21 - 25

Conference paper / Rad u zborniku

Publication status / Verzija rada: Published version / Objavljena verzija rada (izdavačev PDF)

https://doi.org/10.31664/z4khpu.03

Permanent link / Trajna poveznica: https:/urn.nsk.hr/urn:nbn:hr:254:567155

Rights / Prava: Attribution 4.0 International/Imenovanje 4.0 međunarodna

Download date / Datum preuzimanja: 2023-04-26

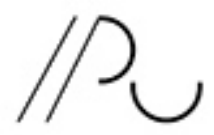

INSITIUT ZA POVIJEST UMJETNOSI
Repository / Repozitorij:

PODEST - Institute of Art History Repository

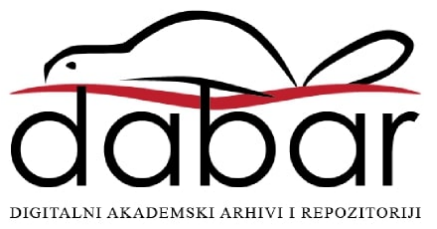




\section{Kabinet grafike Hrvatske akademije znanosti i umjetnosti: formiranje i profiliranje specijalističke muzejsko-galerijske institucije}

Kabinet grafike jedinstvena je specijalistička muzejsko-galerijska institucija koja djeluje u okviru Hrvatske akademije znanosti i umjetnosti. Za razliku od brojnih hrvatskih zbirki umjetnina na papiru smještenih u velikim državnim i gradskim muzejima (Zagreb, Rijeka, Split, Osijek, Dubrovnik)', Kabinet grafike djeluje kao cjelovita brižno profilirana institucija s odgovarajućim prostorima za rad, obradu i proučavanje, izlaganje, opremanje i čuvanje građe, s razvijenom izložbenom, izdavačkom i pedagoškom djelatnošću. Posebnost Kabineta grafike primjereno je opremljen Odjel kalkografije, ${ }^{2}$ u kojem se tiskaju pojedinačni grafički listovi i grafičke mape suvremenih hrvatskih umjetnika.

Prema vrsti i opsegu djelatnosti, vrsti i broju zbirki razlikuje se i od Grafičke zbirke Nacionalne i sveučilišne knjižnice u Zagrebu. ${ }^{3}$ Kabinet grafike broji više od 23.000 umjetničkih predmeta (grafika, crteža, umjetničkih plakata) razvrstanih u tri zbirke, kojima je pridružena mala zbirka grafičkih matrica. U primjereno opremljenu izložbenom prostoru kontinuirano se organiziraju samostalne ili skupne autorske, tematske, problemske izložbe iz bogatoga fundusa. Obrađenu građu prezentiramo u stručnim i znanstvenim katalozima, a posredovanjem Hrvatskoga trijenala grafike ili Hrvatskoga trijenala crteža, izložbama nagrađenih umjetnika valoriziramo suvremeno umjetničko stvaralaštvo, a potom i dopunjavamo zbirke. Prezentirani sadržaji kvalitativna su dopuna događanjima muzejsko-galerijskih institucija u gradu Zagrebu i Republici Hrvatskoj.

Kabinet grafike osnovan je I9I6. godine u okviru Umjetničkog razreda JAZU kao Odsjek Strossmayerove galerije. Tek I95I. godine dobiva upravitelja, I952. čuvaonicu, radne i izložbene prostore na Strossmayerovu trgu u Zagrebu, gdje se i danas nalazi (sl. I), a izložbom bakropisa Jacquesa Callota iz Valvasorove zbirke I954. godine započinje javno djelovanje. ${ }^{4}$ Prvotni naziv Grafički kabinet-Kupferstichkabinett preuzet je od europskih zbirki (Berlin, Dresden, Basel) koje prikupljaju, čuvaju, obrađuju,

\section{Slavica Marković}

Kabinet grafike

Hrvatska akademija znanosti i umjetnosti smarkovic1954@gmail.com

(iD) https://orcid.org/oooo-0oo2-0889-6r93
I Muzej za umjetnost i obrt, Muzej suvremene umjetnosti, Hrvatski povijesni muzej u Zagrebu, Muzej moderne i suvremene umjetnosti u Rijeci, Umjetnička galerija u Splitu, Muzej likovnih umjetnosti u Osijeku, Umjetnička galerija u Dubrovniku itd.

2 Kalkografija Kabineta grafike otvorena je javnosti I997. godine.

3 Grafička zbirka NsK pravi je tip institucije zatvorenoga tipa s prostorom čitaonice i studijske knjižnice. Nema izložbeni prostor niti razvijenu izložbenu djelatnost vezanu uz obradu, stručno i znanstveno publiciranje zbirki. Ima veliku zbirku razglednica, ex librisa i stripa, dok je Kabinet grafike ograničen na zbirke crteža, grafika i umjetničkoga plakata.

4 SLAVICA MARKOVIĆ, Kabinet grafike Hrvatske akademije znanosti i umjetnosti, u: Vijesti muzealaca $i$ konzervatora, Zagreb, 20I4., 26-3I, 26.

Slika I

Sjedište Kabineta grafike HAZU

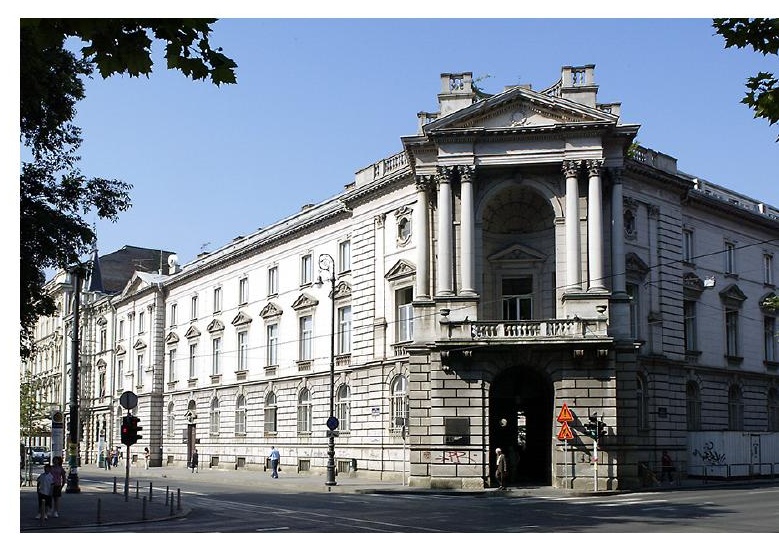


prezentiraju i publiciraju umjetnine na papiru. Standardi obrade građe i prezentacije umjetnina na papiru preuzimaju se od bečke Albertine.

Četiri su teme na koje želimo posebno skrenuti pozornost kada govorimo o specifičnostima Kabineta grafike:

I. nepostojanje stalnoga postava

2. povremene izložbe kao oblik prezentacije zbirki

3. publiciranje stručnog i znanstvenog rada i grafičko izdavaštvo

4. zaštita i čuvanje umjetnina na papiru.

\section{Nepostojanje stalnoga postava. Zašto?}

Kabinet grafike nikada nije imao stalnoga postava i po tome se razlikuje od ostalih muzejsko-galerijskih institucija. Po tipu, sličan je europskim kabinetima grafike i crteža, koji također nemaju stalnih postava. Već iz naziva kabinet može se zaključiti da je riječ o zatvorenom tipu institucije, primarno namijenjene proučavanju i istraživanju, a tek povremeno izlaganju umjetnina na papiru. Zašto?

Papirna građa iznimno je osjetljiva na zračenja. „Elektromagnetska su zračenja izvor energije koja generira kemijske i fotokemijske reakcije, a one mijenjaju svojstva materijala. Promjene koje nastaju u materijalima izloženima elektromagnetskim zračenjima (dakle i svjetlosti) nepovratne su (ireverzibilne) i akumuliraju se. One često na prvi pogled nisu uočljive, ali se na umjetnini kumuliraju za cijelog njezina trajanja. [...] Svako je elektromagnetsko zračenje štetno za umjetnine, no štete najčešće nastaju od izloženosti UV zračenju, IC zračenju i vidljivoj svjetlosti." ${ }^{\text {S }}$ Svjetlost mijenja fizičku i kemijsku strukturu papira, stoga je važno da umjetnine na papiru izlažemo u primjereno osvijetljenim izložbenim prostorima. Dnevna ili muzejska, umjetna rasvjeta, izravna ili neizravna, tijekom vremena uzrokuje izbljeđivanje, lomljivost, krtost papira, trajno briše crtež, čak do potpuna nestajanja.

Spoznaje o posljedicama dugotrajna izlaganja obvezuju nas da čuvamo umjetničko nasljeđe u skladu s najvišim standardima suvremene muzeologije i za generacije koje dolaze. U izložbenim prostorima i čuvaonicama optimalna jačina svjetlosti je 5 o luksa. Izlaganje u takvim, muzejskim uvjetima ne bi smjelo biti duže od devedeset dana. Preporučuje se zamjena originala faksimilima, kao legitimna metoda kojom se koriste druge europske institucije kada neke važne projekte žele pokazati u dužem razdoblju na više lokacija.

\section{Povremene izložbe kao oblik prezentacije zbirki}

Kabinet grafike nema stalnoga postava, no u primjerenom izložbenom prostoru organiziraju se povremene autorske i tematske izložbe crteža i grafika iz Stare zbirke i zbirki ıg., 20. i 2I. stoljeća, autorske, skupne i tematske izložbe plakata, revijalne i problemske izložbe u sklopu Hrvatskoga trijenala crteža ili Hrvatskoga trijenala grafike.
作 preventivne zaštite umjetnina na papiru, Zagreb, 20I0., 37 . 
U skladu s programom, planski pokazujemo naše zbirke. Rezultati su to istraživanja i proučavanja opusa pojedinih autora, područja, tema. Takva istraživanja redovito prate znanstveni katalozi (Juraj Julije Klović u grafici, Martin Rota Kolunić i Natale Bonifacio, Grafika u Italiji i6. i I7. st., Crteži starih talijanskih majstora, Krajolik u grafici starih majstora...). Tu su i suradnje na izložbenim projektima s drugim institucijama (Skice $i$ crteži münchenskih đaka iz fundusa Kabineta grafike). Zbirka 20. i 2I. stoljeća kontinuirano se dopunjuje donacijama istaknutih umjetnika koje nakon obrade izlažemo javnosti. Slikarska i kiparska ostvarenja na našim su izložbama samo komparativna građa sa svrhom ispravne valorizacije pojedinog opusa (Dubravka Babić, Slavko Šohaj, Dušan Džamonja, Branko Suhy, Zlatko Bourek, Ivan Picelj, Antun Babić...). Posebna je pozornost posvećena umjetničkom plakatu. Organizirane su brojne tematske izložbe (Turistički plakat, Sportski plakat, Filmski plakat, Kazališni plakat, Stoljeće hrvatskog plakata). Predstavljeni su i valorizirani prvaci hrvatskog plakata, akademici (Csikos, Crnčić, Krizman, Babić) i majstori hrvatskoga plakata: Sergije Glumac i Pavao Gavranić, Bojan Stranić.

S ciljem popularizacije i ispravne valorizacije crteža i grafike, komunikacije sa suvremenom umjetnošću, pokrenute su bijenalne jugoslavenske izložbe grafike i jugoslavenske izložbe crteža (I960., I968.). Promijenivši koncepciju, te su manifestacije prerasle u Hrvatski trijenale crteža (I996.) i Hrvatski trijenale grafike (I997.) kao oblik prezentacije i valorizacije suvremenih umjetničkih pojava u medijima crteža i grafike. Zbog složene koncepcije i broja događanja središnje manifestacije Trijenala odvijaju se u velikim gradskim izložbenim prostorima (Umjetnički paviljon, HDLU, Klovićevi dvori...), a prateće u Kabinetu grafike. Budući da traju mjesecima, tema grafike ili crteža dio je kulturne ponude grada. Takvim je izlagačkim programom Kabinet grafike nadoknadio nepostojanje stalnoga postava, a organiziranjem Trijenala osigurao kvalitetan uvid u recentno stvaralaštvo u medijima crteža i grafike (sl. 2, 3).
Slika 2

Izložbena djelatnost

Kabineta grafike HAZU,

2014 .

Slika 3

Izložbeni prostor

Kabineta grafike HAZU
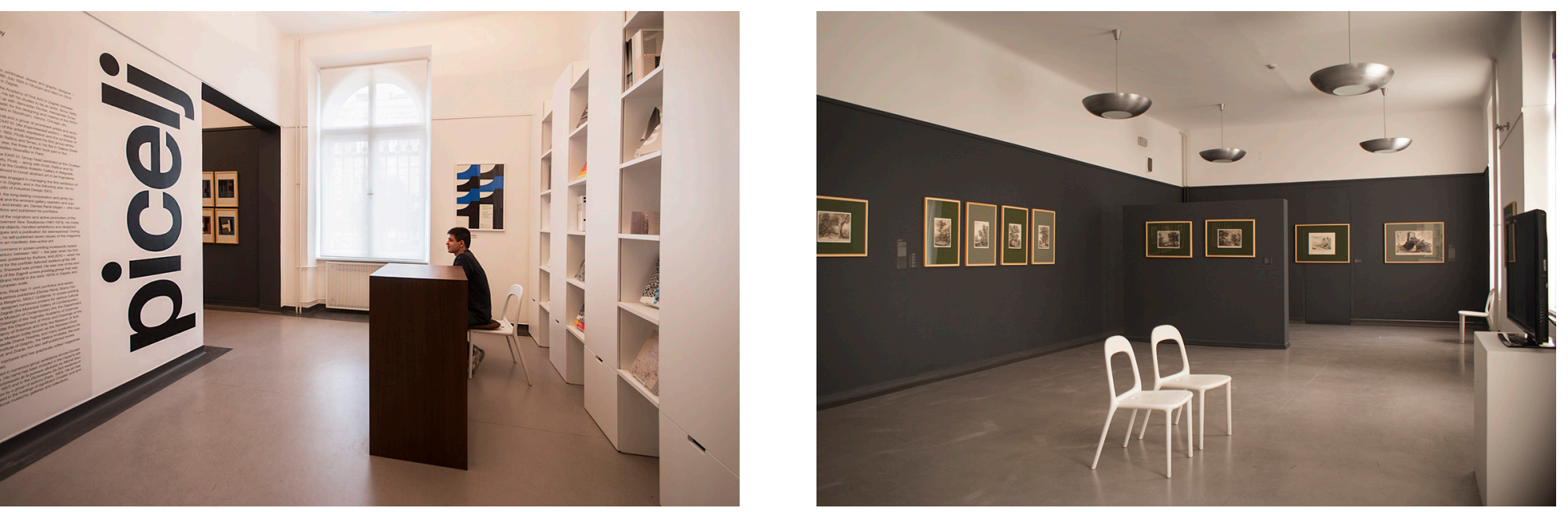


\section{Izdavaštvo Kabineta grafike}

Od I99I. godine, kada sam preuzela dužnost upraviteljice Kabineta grafike, posebnu pozornost (pored svega prethodno navedena) obraćamo publiciranju zbirki i grafičkome izdavaštvu. Izložbene projekte prate katalozi i multimedijske interaktivne publikacije, CD-i ili DVD-i. Naši katalozi razlikuju se po obradi, opsegu, formatu i dizajnu, ovisno o zbirci kojoj pripadaju i sadržaju koji prezentiraju (sl. 4).

Zasebna je edicija likovnih monografija u kojoj obrađujemo i prezentiramo selekcije crteža i grafika istaknutih hrvatskih umjetnika, donatora Kabineta grafike. Multimedijske interaktivne publikacije, CD-i i DVD-i dopuna su izložbenim projektima jer sadrže različite video sadržaje: manje dokumentarne filmove, video šetnje izložbenim prostorima, intervjue $\mathrm{s}$ autorima i likovnim kritičarima, TV emisije, a na svakom je disku i PDF tiskanoga kataloga s mogućnošću ispisa. Ti sadržaji dragocjeni su nakon završetka izložbi, kada je potrebno rekonstruirati dionice, pojedinosti ili događaje koji nisu mogli biti prikazani u tiskanim publikacijama.

Grafičko izdavaštvo osobitost je Kabineta grafike koju želim posebno istaknuti. Od I997. godine u sklopu Kabineta grafike razvija se Odjel kalkografije kojemu pripada zbirka grafičkih ploča koje su realizirali umjetnici prve polovine 2o. stoljeća. Osim što se povremeno u malim nakladama, poštujući stroge uzuse struke, otiskuju tzv. kalkografski otisci s originalnih matrica, kalkografija je osnova za suvremeno grafičko izdavaštvo, produkciju naklada grafičkih mapa i prezentaciju metoda pripreme i otiskivanja grafičkih listova u obliku različitih pedagoških radionica za djecu i odrasle (sl. 5).

Nakon Trijenala grafike izdaju se grafičke mape izabranih, nagrađenih grafičara, a između 6.i 7. trijenala grafike pokrenut je projekt Argola (sl. 6). Argolu smo pokrenuli 20I3. godine s namjerom intenzivnije komunikacije sa suvremenim hrvatskim grafičarima, promocije njihovih recentnih poetika, poticanja primjene plemenitih grafičkih tehnika, stvaranja grafičkoga niza koji reflektira pulsiranje hrvatske grafičke scene. Nizanjem aktualnih poetika vitalnih kreatora hrvatske grafike izgradit ćemo zajedno tijekom sljedećega razdoblja živo grafičko polje u kojem komuniciraju doajeni hrvatske grafičke umjetnosti s novim valom darovitih mladih grafičara koji danas vitalno stasaju u sva četiri hrvatska umjetnička središta-na akademijama u Zagrebu, Rijeci, Osijeku i Splitu. Misija je edicije Argola vraćanje izgubljenog digniteta originalnoj grafici i skretanje pozornosti ljubitelja umjetnosti na specifičnost i vrijednost dubokoga, visokoga, plošnoga tiska i svih autentičnih inačica nastalih kombiniranjem tradicionalnih i suvremenih metoda u pripremanju i otiskivanju grafičkoga lista, a napose skretanje pozornosti na autore takve grafike.
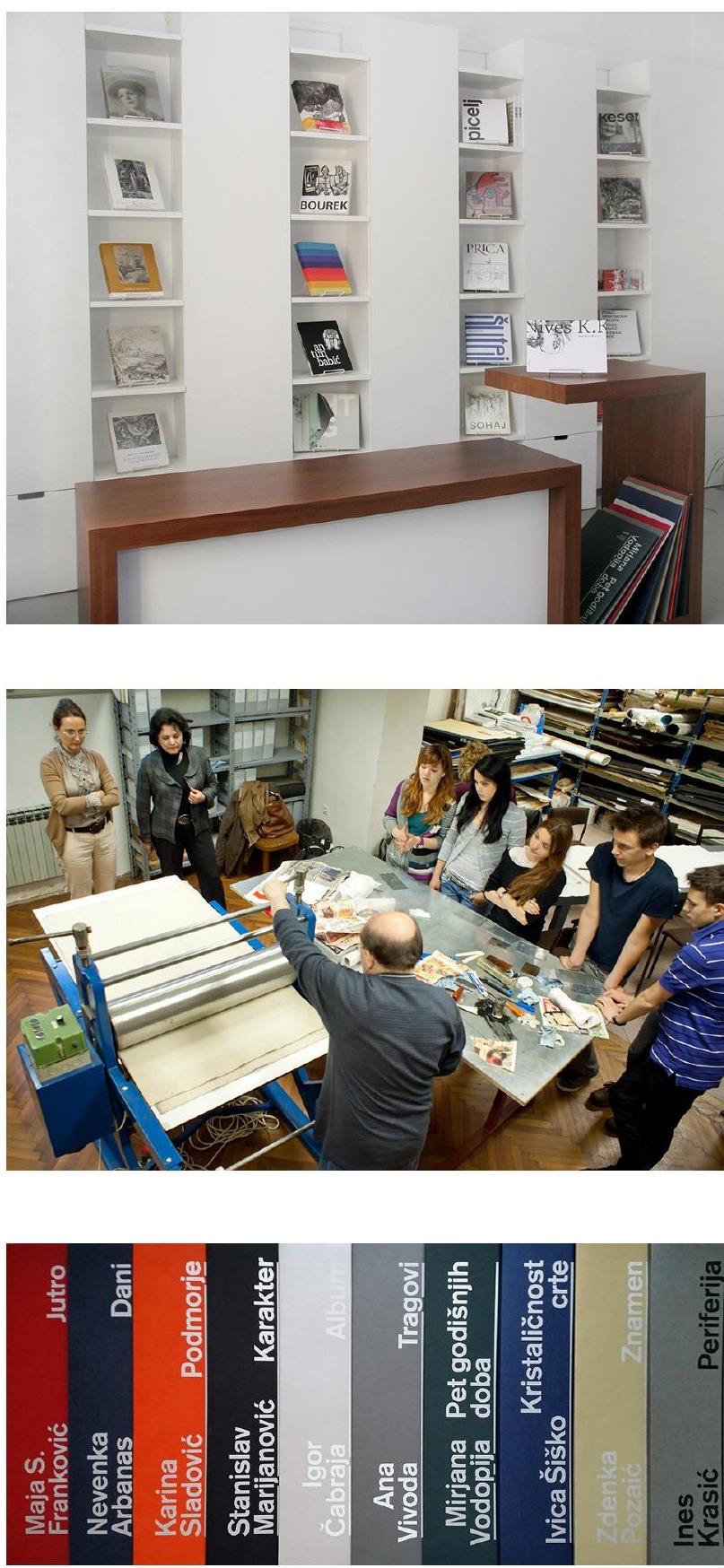

Slika 4

Izdanja Kabineta grafike HAZU

Slika 5

Pedagoška radionica u organizaciji Kabineta grafike HAZU

Slika 6

Edicija grafičkih mapa Argola 


\section{Zaštita i čuvanje umjetnina na papiru}

Visoke standarde čuvanja i zaštite građe ostvarili smo u čuvaonicama opremljenima ladičarima i specijalnim metalnim ormarima. Umjetnine na papiru pohranjene su u pH-neutralne paspartue, zaštićene prozirnim antistatik $\mathrm{pH}-n$ eutralnim folijama Melinex, uložene u $\mathrm{pH}$-neutralne arhivske mape, potom odložene u ladičare (sl. 7, 8). Tako opremljena građa čuva se u uvjetima relativno stabilne mikroklime. ${ }^{6}$ Izložbe organiziramo u prostorima s kontroliranim neizravnim osvjetljenjem i led-rasvjetom s UV-filterima s preporučenom jačinom svjetlosti oko 5o luksa. Prozori su zaštićeni UV-folijama i transparentnim zastorima, a vrijeme izlaganja ovisno o vrijednosti i stanju umjetnine ograničavamo na četrdeset odnosno devedeset dana. Isto propisujemo onima koji posuđuju našu građu za izlaganje u okviru svojih projekata. Nakon povratka $\mathrm{u}$ čuvaonicu obvezatno je višemjesečno mirovanje umjetnine kako bi se stabilizirali kemijski procesi izazvani djelovanjem svjetlosti i temperaturnih razlika.

Na usluzi smo svima koji pripremaju kompleksne izložbene projekte ako su umjetnine iz našega fundusa kvalitativna dopuna tim projektima. Građa se može pregledavati u našim prostorima čitaonica, a za izlaganje se mogu posuditi isključivo opremljeni radovi. Manipuliranje originalima, paspartuiranje, fiksiranje, uokviravanje nije dopušteno vanjskim suradnicima, nego to obavljaju muzejski stručnjaci Kabineta grafike. Taj je kućni standard uspostavljen isključivo radi zaštite umjetnina na papiru, u skladu s europskim standardima posudbe originala.

Kabinet grafike osnovan je kao Odsjek Strossmayerove galerije starih majstora i kao brojne druge institucije mogao je ostati u njezinim okvirima. Svi veći hrvatski muzeji, a posebice Grafička zbirka NSK, imaju zbirke crteža i grafika koje vrlo rijetko pokazuju javnosti. Kabinet grafike HAZU kontinuiranom, strogo profiliranom izložbenom i izdavačkom djelatnošću, pedagoškim aktivnostima kojima dopunjava javno djelovanje, a posebice grafičkim izdavaštvom, brižno gradi i njeguje jasan profil specijalističke muzejsko-galerijske institucije jedinstvene u Hrvatskoj.

\section{() (1)}

Kabinet grafike Hrvatske akademije znanosti i umjetnosti: formiranje i profiliranje specijalističke muzejsko-galerijske institucije/ Slavica Marković / CC BY / 4.o

DOI: https://doi.org/Io.3I664/z4khpu.o3
6 U planu je klimatizacija cijeloga prostora, a time i apsolutna kontrola mikroklime u svim prostorima Kabineta grafike.
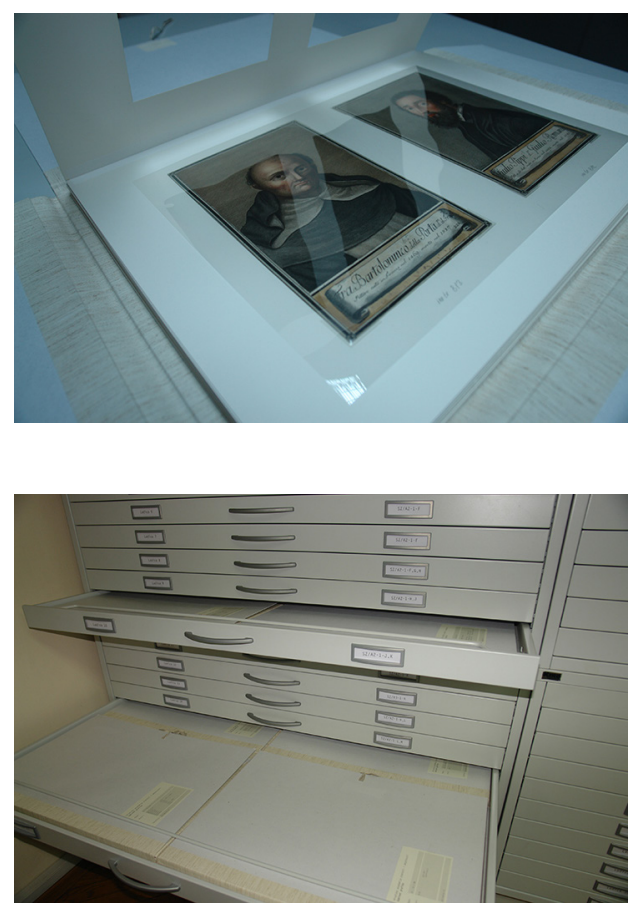

Slika 7 Oprema umjetnina na papiru

Slika 8 Ladičari za pohranu građe $u$ Kabinetu grafike HAZU 